\title{
Los grabados de túmulos efímeros en Lima colonial
}

\author{
Ricardo Estabridis Cárdenas \\ Departamento Académico de Arte
}

\section{PROLOGO}

El grabado constituye en nuestro país una de las manifestaciones plásticas menos estudiada y una forma de expresión de singular importancia sobre todo en años coloniales, no sólo desde el punto de vista estético o creativo, sino por su carácter documental al estar ligado estrechamente a la evolución de la imprenta y a la producción bibliográfica. Ello nos motivó para la investigación y publicación de un ensayo sobre el grabado colonial en Lima, editado en Sevilla al cumplirse los cuatrocientos años de la creación de la imprenta en el Perú1.

A la fecha es nuestro deseot sumar a dichas líneas el presente trabajo de investigación, dedicado extersivarfentea los grabades de túmulos funerarios que ilustraron los libros de las exequias, salidos de las imprentas limeñas a lo largo de todo el periodo colonial.

Es necesario anotar que en la producción bibliográfica en el Perú no existe ningún trabajo de investigación publicado sobre el tema de los grabados de túmulos funerarios ${ }^{2}$. En España Rafael Ramos Sosa dentro de su publicación sobre el arte festivo en Lima Virreinal, se ocupa de las fiestas luctuosas y aporta información sobre los túmulos, sin embargo sólo abarca hasta el siglo XVII³.

Estabridis Cárdenas, Ricardo, "El grabado colonial en Limam, Anuario de Estudios Americanos. Tomo XLI. Sevilla. 1984

2. El libro de José Abel Fernández, Grabadores en el Perí, Lima, 1995, toca muy superficialmente el grabado colonial.

1 Ramos Sosa, Rafael, Arte festivo en Lima virreinal siglos XVI-XVII. Sevilla, 1992.

Letras (Lima), 95-96: 33-66, 1998. 


\section{INTRODUCCION}

La fiesta entendida como acontecimiento de la vida humana comprende también lo luctuoso, es decir, la manifestación del dolor por la muerte de un ser amado. En Lima Colonial, así como se celebraron fiestas profanas por la llegada de los virreyes, proclamación de reyes o nacimientos de príncipes y fiestas religiosas con desfiles procesionales, representaciones teatrales y fuegos artificiales, también se celebraron pompas fúnebres por la muerte de un personaje real, Papa o arzobispo, con similar despliegue de manifestaciones culturales, que incluían la metamorfosis del lugar de la fiesta con el llamado arte efímero.

Las fiestas se expresaban a través del arte y el conocimiento de dichas creaciones, aunque efímeras, han dado nuevas luces sobre la cultura de la sociedad limeña colonial. Han llegado a nosotros informes de virreyes y arzobispos, y a partir del siglo XVII las relaciones impresas que incluían una descripción detallada de las fiestas. En el caso de las relaciones de exequias se incluía por lo general, aparte del retrato del difunto, el grabado del túmulo levantado en el recinto catedralicio.

En lo que respecta al siglo XVI, manuscritos de la época demuestran que desde fechas tempranas se celebraron exequias por la emperatriz Isabel en

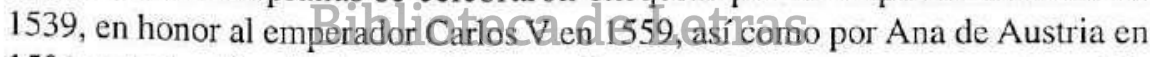
1581, pero los túmulos]levantadoscnọse llè en 1584 Antonio Ricardo se instala en Lima, dando inicio a la imprenta en el Virreinato del Perú. Es debido a ello que el expediente acostumbrado que enviaban las autoridades al Consejo de Indias, dando razón de las exequias celebradas será sustituido a partir del siglo XVII por un libro impreso.

Los libros de exequias editados por las imprentas limeñas en el siglo XVII, contenían en detalle todo el acontecimiento propiciado desde la llegada de la noticia del fallecimiento en España del personaje real, los preparativos para la ceremonia, el protocolo en las procesiones, los sermones y una descripción del túmulo, diseñado por lo general por un arquitecto de prestigio en Lima, como veremos en el desarrollo de este trabajo.

En cuanto al aspecto formal arquitectónico, en un principio existe una cierta dependencia de los túmı los limeños con los estructurados en España, pero más adelante, en el último tercio del siglo XVII, la arquitectura limeña efímera adquiere características particulares con respecto a la península. 
Es necesario considerar que en su conjunto el túmulo, además de la arquitectura, comprendería esculturas y pinturas que obedecían a un programa iconográfico, preparado por un intelectual de la época, por lo general procedente de las cátedras de la Universidad de San Marcos. La mayoría de las descripciones de estos programas dan cuenta de la erudición del intelectual y del espíritu de la época, inmerso dentro de un arcaizante humanismo renacentista, donde se trata de resaltar las cualidades y virtudes del difunto, en un afán de trascendencia histórica. Con el fin de conseguir dicho objetivo no se dejó de lado en los programas las alegorías, jeroglíficos, emblemas y hasta pinturas de temas mitológicos, no considerados en la plástica de la vida cotidiana, desarrollo de los estilos en la arquitectura limeña.

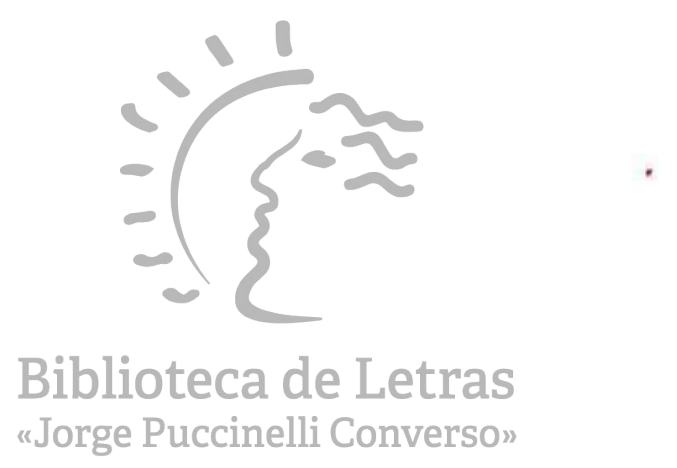




\section{LOS GRABADOS DE TUMULOS EN EL SIGLO XVII}

\section{Antecedentes del grabado en Lima}

Apenas pasadas las dos primeras décadas de la Conquista se fundaron en tierras americanas centros de estudios superiores y estos determinaron la necesidad de establecer la imprenta que satisfaga las inquietudes de los estudiosos y apoye la difusión de la fe. En Lima la erudición literaria se manifiesta desde el momento en que se funda, el 12 de mayo de 1551, la Universidad de San Marcos en los claustros dominicos por fray Tomás de San Martín, casa de estudios con iguales prerrogativas que la Universidad de la humanista Salamanca, sin embargo tuvo que esperar tres décadas los permisos reales para el establecimiento de la primera imprenta. Es así como en 1584, vio la luz el primer libro producido en América Meridional: la Doctrina Cristiana, salido de la imprenta del italiano Antonio Ricardo ${ }^{4.5}$.

Ya desde los inicios del grabado en el Perú se van a poner de manifiesto los géneros básicos de producción retratos, figuras alegóricas, escudos, diseños arquitectónicos y las infaltables estampas religiosas; todos ellos se mantendrán hasta el epílogo colonial y evolucionarán en su aspecto técnico y creativo.

En los escasos dieciséis años que restaban para concluir el siglo XVI, la producción de grabados fue exigua y todos los conocidos hasta el momento permanecen en el anonimato ja queningụo fue firmado por el creador, ni impresor. Se plantea la posibilidad dejautoría entrealgunos de los nombres de colaboradores que trabajaron con Antonio Ricardo, tales como Pedro Pareja, Gaspar de Almanzón, Pedro Alvarez, Juan García y Pedro Alvarez Portichuelo ${ }^{6}$ e incluso el mismo Ricardo.

El grabado, nueva forma de expresión artística en Lima Colonial nace dentro del periodo en que predomina la influencia italiana por la presencia en la Ciudad de los Reyes, no sólo de obras de «buena mano romana», como citan los documentos de archivo, sino además por la presencia de la trilogía de pintores italianos considerados pilares de nuestra pintura colonial: el hermano je-

4 Antonio Manuel Rodríguez-Buckingham, Colonial Peru and the printing press of Antonio Ricardo. Tesis, Ph.D. University of Michigan, 1977.

5 Archivo General de la Nación, Codicilio otorgado ante el escribano Dan. Juan Manuel con fecha 25 de abril de 1586 , según registro, ff. $9 / 10$.

6 Pardo Sandoval. Teresa, "Impresos peruanos del siglo XVI: ornamentación. tipografia y encuadernación". Boletin del Instituto Riva-Agitero, No 17. Lima, 1990, p. 231. 
suita Bernardo Bitti, Mateo Pérez de Alesio y Angelino Medoro ${ }^{7}$. No se puede descartar las preferencias del italiano Antonio Ricardo en las primeras estampas que salieron de su imprenta.

La técnica usada en la mayoría de estos primeros libros es la xilografía, grabado en relieve sobre madera que se desarrolló a principios del siglo XV en los Países Bajos, Alemania y Francia y que agota sus posibilidades expresivas en la primera mitad del siglo siguiente, dando paso al grabado en cobre, técnica que alcanzará un éxito inmediato y constituirá la forma más importante de grabado hasta el segundo decenio del siglo pasado.

En Lima la xilografía se seguirá usando hasta finalizar el siglo XVI.

\section{Francisco Bejarano y el túmulo de Margarita de Austria}

Mateo Pérez de Alesio ejerció la doeencia artística por un espacio que según documentos de la época superó el cuarto de siglo. Entre sus discípulos el más destacado fue el agustino Francisco Bejarano como lo afirman crónicas y otros escritos; a pesar de que hasta el momento no se ha podido identificar ninguna de sus pinturas, nos ha sido posible apreciar su obra como grabador en libros de la época.

Las primeras noticias sobre Bejarano las encontramos en un documento fechado en 29 de octubre de' 800 . Por éf consta que hacia un año que estaba de aprendiz en el obrador de su maestro y con el propósito de aprender todas las artes de la pintura prolongaba su compromiso por tres años más ${ }^{8}$. Es indudable que el contrato determina que en los cuatro años que está bajo el magisterio del pintor le enseñaba todas las técnicas, incluso las del grabado calcográfico.

Más tarde Bejarano entrará en la orden agustina. El cronista agustino fray Antonio de la Calancha al describir el esplendor del convento a comienzos del siglo XVII, lo cita como fraile agustino y excelente pintor ${ }^{9}$. De toda la labor

Estabridis Cárdenas, Ricardo, «Influencia italiana en la pintura virreinal». Pintura en el Virreinato en el Perii, Lima, 1989, p. 109.

- Lohmann Villena, Guillermo, aNoticias inéditas para ilustrar la historia de las bellas artes en Lima durante los siglos XVI y XVII», Revista Histórica, Tomo XIII, Lima, 1940, p. 11.

- Calancha, Fray Antonio de la, Crónica moralizadora del Orden de San Agustín en el Perí... Libro I. Barcelona, 1638. Libro I, Cap. XXXIX, fol. 248. 
pictórica para la iglesia de San Agustín de Lima descrita detalladamente por el cronista no ha llegado nada hasta nosotros, todo se perdió en el fuerte sismo de 1687.

Entre los documentos que hablan de Bejarano, el más fructífero ha sido el del padre Rubén Vargas Ugarte, quien lo documenta como limeño y cita su actividad como grabador ${ }^{10}$.

Una de las fuentes más importantes para el estudio de los grabados coloniales la constituyen los libros sobre las exequias por la muerte de algún personaje real o dignidad eclesiástica, ya que en sus ediciones, aparte de los preparativos, ceremonias y descripciones del túmulo, eran incluidos, escudos, retratos, y al final una gran lámina de mayor formato que perennizaba el túmulo levantado en la Ciudad de los Reyes.

El primer libro que incluyó en Lima los tipos de grabados citados, fue el de fray Martín de León", salido de la imprenta de Pedro de Merchán en 1613. En él encontramos información de suma/importancia, como por ejemplo en el folio $3 \mathrm{v}$ se menciona:

«mandó que los maestros de arquitectura hiziesen diferentes plantas para el túmulo y aviendolas visto y que qualquiera de ellas fuera bastante porque eran grandes artífices, hizo eleccion de la de Juan Martínez de Arrona, maestro mayor mereèđamente de las obras de este reino, que sufecomparacion seaventajo a las demas" (sic).

En el folio 4v. certifica:

«este es el primero después del túmulo que hizo la ilustrísima ciudad de Sevilla a las honras del rey Don Philipe Segundo nuestro Señor. Algo se vera en su estampa (algo) que por ser la primera vez que esta forma de estampar le dio principio en este reino, no fue posible sacarse con mayor perfeccion y lo que no pudo dar a entender el buril en la siguiente descripcion se vera».

La descripción amplia y detallada permite tener una idea de la magnificencia arquitectónica, donde esculturas y pinturas se alternan en base a un com-

\footnotetext{
Vargas Ugarte, Rubén, Ensayo de un diccionario de artífices coloniales. Lima, 1947, p. 133.

León, Fray Martín de, Relación de las exequias de la Reina Margarita de Austria... Lima, 1613.
} 
plejo programa iconográfico que resume el espíritu de la época en que vivió nuestro artista. Un buen ejemplo de ello lo vemos en uno de los lienzos, donde aparece la muerte sentada sobre un sepulcro con una perla en las manos y delante de ella la ciudad de Lima con hábito triste de mujer que le ofrece las tres coronas de sus armas. Encima este mote: La que más, lo menos y debajo:

Pues llevas mi Margarita
y tanto de ello blasonas
llévate mis tres coronas.

El libro de las exequias de la reina Margarita contiene los dos primeros grabados firmados provenientes de las imprentas limeñas. El primero de ellos, fechado por Bejarano en 1612: Franciscus debexarano Augustiniensis scudebat 1612 Lima, representa el escudo en el frontispicio, donde se indica que las mandó hacer el virrey Juan de Mendoza y Luna, marqués de Montesclaros y el segundo la estampa del túmulo levantado en la Catedral de Lima, firmado en 1613; lastimosamente esta segunda estampa yano se ubica en el libro consultado en la Biblioteca Nacional del Perú sinembargo fue hallada en un ejemplar de la Biblioteca del Congreso de Diputados de Madrid Adita Allo Manero' ${ }^{12}$. (Lám. 1).

En la estampa publicada por Ramos Sosa se puede observar un túmulo de dos cuerpos, donde se superponen los órdenes dórico y jónico y se comprueba la descripción del libro al ver lantucusien de figuras alegóricas para destacar las virtudes de la reina, igualmejte decheronlas deliAntiguro Testamento, de santas con su nombre, así como alegorías de las cuatro partes del mundo.

En cuanto al esquema básico, el túmulo limeño responde a los caracteres compositivos del que hizo en Sevilla Juan de Oviedo en 1598 a la memoria de Felipe II y que fuera llevado a la estampa por Diego López Bueno. Ramos Sosa ha realizado un estudio comparativo detallado entre ambos túmulos. Asimismo, es importante tomar en cuenta la relación del diseño central del túmulo de Martínez de Arrona con el diseño que hiciera para la portada principal de la Catedral de Lima.

12 Ramos Sosa, Rafael, Op. cit., p. 144 


\section{Guillermo de Oliva y el túmulo de Isabel de Borbón}

Antes de promediar la primera mitad del siglo XVII muere la reina Isabel de Borbón, en 1644, y las honras fúnebres a su memoria se dispusieron en Lima para los días 1 y 2 de junio de 1645 , exequias perennizadas en el libro de Gonzalo Astete de Ulloa ${ }^{13}$.

Tanto el desarrollo del texto como la firma que figura en la estampa del túmulo que lo ilustra, nos informa que el autor del diseño fue el maestro mayor de la Catedral de Lima por aquellos años, Pedro de Noguera, natural de Barcelona, España. En base a este documento se sabe que Noguera tuvo como referencia un modelo peninsular no identificado, pero prometió reformarlo y mejorarlo. Asimismo se tienen noticias del concierto con Juan de Arce quien se encargaría del pintado y dorado del túmulo, de las dieciséis figuras alegóricas y las doce banderas ${ }^{14}$.

Después del ensayo que publicaramos en Sevilla sobre el tema del grabado, donde no incluimos la estampa del túmulo de la Reina porque no existía en el ejemplar consultado en la Biblioteca Nacional de Lima, en nuestra búsqueda, la ubicamos en la Biblioteca de la Recoleta de Arequipa. La lámina aún está unida al libro y es de un formato nueve veces mayor que el de los folios de la Relación ${ }^{15}$. (Lám. 2).

En la parte superioi de laqúnina selee:- Letras "Jorge Puccinelli Converso"

«Diseño del Túmulo Real que el Excmo. S.D. Po. de Toledo Marqués de Mansera Virrei del Perú Hizo en las Honras de la Serenísima Reina de España Doña Isabel de Borbón Nuestra Señora».

En la zona inferior figuran las firmas de Noguera y de Guillermo de Oliva, este último aún sin documentar y del cual por el momento sólo esta obra da fe de su actividad en las artes calcográficas.

\footnotetext{
13 Astete de Ulloa, Gonzalo, Pompa fínehre y exequias... en la muerte de... Isabel de Borbón. Lima. 1645.

14 Harth-terré. Emilio, Escultores españoles en el Virreinato del Perí. Lima, 1977. p. 145.

15 Debemos reconocer que Lorene Pouncey ha sido la primera en publicarlo en "Túmulos of Colonial Peru", The Art Bulletin. Vol. LXVII. No 1. marzo, 1985.
} 
La estampa del túmulo de Isabel de Borbón muestra un monumento ochavado, al parecer de planta octogonal y elevado en tres cuerpos decrecientes con columnas dóricas. El primer cuerpo alberga el catafalco con las insignias reales, custodiado por leones sedentes y delante de las columnas los reyes de armas correspondientes a Sevilla, Granada, Toledo, Vizcaya, Navarra, Aragón, Sicilia y Portugal; en el segundo cuerpo, al centro la figura de la Reina de pie y sobre los ejes de las columnas del primer cuerpo, figuras de cuerpo entero de cuatro emperatrices y cuatro reinas; el tercer cuerpo con ocho imágenes alegóricas de virtudes que en similar distribución a los personajes reales se ubican en los ejes de las columnas. Toda la estructura arquitectónica remata en cupulín coronado con un obelisco y un ave fénix sobre un globo terráqueo, como símbolo de inmortalidad. Son ostensibles igualmente las banderolas pintadas con las armas del Rey por Juan de Arce, aunque no la serie de alegorías pintadas que da cuenta el libro de las exequias, así como los versos que exaltan el triunfo de su memoria sobre la muerte, como se hiciera en el túmulo de la Reina Margarita de Austria. En líneas generales podemos anotar que no obstante el programa iconográfico responde ya un un espiritu de lo barroco, el aspecto formal del túmulo llevado a la estampa, refleja caracteres del renacimiento tardío español.

\section{P.A. Delhom y el túnutodo felinedVle Letras}

En la segunda mitadgal-sigloiXqili dosaconteoimientos importantes motivan ceremonias en la capital del virreinato peruano, cuyas relaciones son llevadas a la imprenta perennizándolas no sólo a través de la literatura sino de las artes plásticas, al ser ilustradas con grabados. Una de ellas es motivada por el fallecimiento del rey Felipe IV, ya que se celebraron sus exequias en Lima el 17 de setiembre de 1666, al año de su muerte, y la otra ceremonia ocurrió al mes siguiente, la consabida proclamación del sucesor, el rey Carlos II.

Ambas relaciones fueron escritas por don Diego de León Pinelo, descendiente de un judío portugués, su abuelo, muerto por la inquisición en Lisboa. Después de este acontecimiento sus padres viajaron a Indias a comienzos del siglo XVII y dieron a América a sus tres hijos, todos eminentes ${ }^{16}$, entre ellos Diego, quien llegó a ser rector de la Universidad de San Marcos. 
El primer libro documentado con grabados que nos alcanza don Diego de León Pinelo es: Solemnidad fúnebre y Exequias a la muerte del Católico Augustíssimo Rey Nuestro Señor D. Felipe IV Lima, en la imprenta de Juan de Quevedo, $1666^{17}$. El segundo denominado: Aclamación y Pendones que levantó la Muy Noble y Muy Coronada Ciudad de los Reyes Por el Cabildo y Augustíssimo Rey D. Carlos II..., el mismo año y en la misma imprenta.

Gracias a la relación impresa de León Pinelo, se conoce todo lo acontecido en las exequias de Felipe IV desde su preparación; que el arquitecto y escultor Asensio de Salas fue el autor del túmulo y que P.A. Delhom lo llevó al grabado. El artífice del monumento efímero es conocido sobre todo por su obra en la Catedral: el retablo de la Concepción (1654-56), obra que reúne elementos característicos de la arquitectura limeña de la época ${ }^{18}$, en cambio, del grabador no tenemos noticia alguna, a pesar de que firma en este libro el grabado de la portada y la estampa del túmulo, además del grabado del monumento de Aclamaciones al rey Carlos II, dado a conocer por Rodríguez Camilloni ${ }^{19}$.

El túmulo lo muestra imponente sobre enorme escalinata, desplegado en dos cuerpos decrecientes de planta centralizada y orden dórico, con balaustres y frontones que albergan el escudo real. El primer cuerpo al parecer desarrollado en cruz griega con esculturas de los reyes de armas; en el segundo cuerpo de planta octogonal se aprecian las figuras alegóricas de América, Europa y Afri$\mathrm{ca}$ y todo remata eni imai cứpulaas ebre tamboe igualmente octogonal, flanqueado por las alegorías dela Fe y la Justicia y coronada por la figura alegórica de España con banderola eucarística, como fiel defensora de la fe.

El barroco limeño marcado en la arquitectura de retablos por Asensio de Salas, se hace perceptible en la fachada de San Francisco el Grande de Lima, así como en el monumento efímero mencionado, sobre todo en la tipología de columnas estriadas con paños colgantes, y en esa búsqueda de alternancias y contrastes lumínicos al colocar unas columnas delante de otras, o hacerlas de diferentes tamaños para simular distancias.

\footnotetext{
17 Ramos Sosa, Rafael, Op. cit., p. 169.

18 San Cristóbal, Antonio, Arquitectura virreinal religiosa de Lima. Lima, 1988, p. 59.

19 Rodríguez Camilloni, Humberto, «El conjunto monumental de San Francisco de Lim

XVIIIs, Boletín del Centro de Investigactones Históricas v Estéticas, N 14, Caracas, 1972, p, 49
} 


\section{Fray Pedro Nolasco y el túmulo de Mariana de Austria}

Al igual que el grabador P.A. Delhom, el fraile mercedario Pedro Nolasco destaca en esta rama de las artes plásticas en la segunda mitad del siglo XVII. Medina supone que era de origen francés y que su verdadero apellido era Mere, ${ }^{20}$ y Vargas Ugarte agrega que vino a América hacia 1660 e ingresó a la orden de La Merced en $1663^{21}$.

A diferencia de Bejarano que está documentado además como pintor, Nolasco se dedicó exclusivamente a las técnicas calcográficas;

han llegado hasta nosotros varios de sus grabados que dan muestra de su calidad, con un excelente dibujo, dominio de la perspectiva y claroscuro que refleja el nuevo estilo reinante.

El último grabado documentado de Nolasco data de 1697 y corresponde al túmulo, de doña Mariana de Austria, levantado en la Catedral de Lima con motivo de sus exequias ${ }^{22}$. El ejemplar de la relación de las exequias, consultado en la Biblioteca Nacional de Lima está quemade, presenta hojas sueltas y no aparece el grabado; sin embargo es posible conocerlo gracias a la publicación de Ramos Sosa, ilustrada con la estampa del túmulo real conservada en un ejemplar de la Biblioteca Nacional de Madrid ${ }^{23}$. (Lám. 3).

Mariana de Austriaj madre de Carlos II, murió eld 7 de mayo de 1696 y las exequias se celebraron en Lima los días 4 y 5 de marzo de 1697 con gran túmulo levantado en la Catedral, obra de Fray Cristóbal Caballero, quien tuvo a su cargo el monumento conmemorativo de la proclamación del Rey Carlos II en Lima, treinta años atrás, $y$ al igual que en él refleja los elementos decorativos particulares que adopta la arquitectura limeña avanzado el siglo XVII; en este caso aparte de los rostros coronados con veneras se aprecian modillones y esgrafiados $^{24}$.

Gracias al grabado de Fray Pedro Nolasco pasó a la posteridad este monumento efímero que refleja el espíritu de la época en el programa iconográfico

\footnotetext{
20. Medina, José Toribio, Historia de la imprenta en América y Océania. Santiago de Chile, 1958, p. 479.

a) Vargas Ugarte, Rubén, Op. cit.. p. 224.

:2 Romero González de Violabas. Bernardo de. Funerul pompa... Doña Mariana de Austria... Lima, 1697.

3 Ramos Sosa, Rafael. Op. cit., p. 173.

2. San Cristóbal, Antonio, Op. cit., p. 49.
} 
y en los gustos arquitectónicos de la Lima del XVII. Según la estampa, responde a los túmulos de cuerpos superpuestos decrecientes; en este caso el primer cuerpo de planta octogonal con pilares de base cuadrada decorados con los rostros enconchados con paños colgantes, que sostienen en el ochavo apreciable un arco escarzano y dos laterales de medio punto con veneras. Entre los pilares y sobre pedestales, los reyes de armas. Corona el primer cuerpo una balaustrada donde asoman esculturas de reinas con escudos, que según la relación representan a los reinos de España.

El segundo cuerpo del túmulo de la Reina madre presenta planta cuadrangular con pilastras cajeadas y pareadas, con capiteles en modillón y entre ellas hornacinas con esculturas de alegorías que exaltan las virtudes de Mariana de Austria, tales como: la Justicia, la Fortaleza, la Fe y la Templanza. Al centro de este cuerpo se simuló el túmulo real. El remate al igual que en el cuerpo anterior lleva balaustrada con otras figuras de reinas alegóricas. El monumento efímero termina en dos paramentos cerrados y la cúpula con óculos sobre tambor, la que en lugar de linterna lleva un globo terráqueo sobre el que vuela una paloma con una rama de olivo en el pico, en alusión al alma de la Reina.

El sistema de iluminación es perceptible en las enormes pirámides de luces y en la gran cantidad de hachones que circundan los cuerpos.

El legado gráficode Nolasco, aparte del-túmulo citado, es suficiente para reconocerlo como el grabador más destacado del siglo XVII. Aparte de ello debemos de considerar lo anotado pof Vietor Banrigal Soble los libros corales del Convento de La Merced, miniados por nuestro artista $\mathrm{a}^{25}$.

\section{LOS GRABADOS DE TUMULOS EN EL SIGLO XVIII}

\section{Fray Miguel Adame y el túmulo de Carlos II}

No obstante que la obra conocida de Adame hasta el momento se enmarca entre los años de 1699 y 1731 consideramos que es el mejor exponen-

25 Barriga, Víctor, El templo de La Merced de Lima. Arequipa, 1944, p. 180. 
te del grabado producido en la Ciudad de los Reyes dentro de la primera mitad del siglo XVIII. No se tiene información sobre su lugar y fecha de nacimiento pero sí que perteneció a la Orden de Predicadores del convento dominico de la Virgen del Rosario de Lima ${ }^{26}$, además de que aparte de su labor como grabador está documentado como pintor, así lo certifican dos lienzos conservados en el Monasterio de las Nazarenas de Lima que representan al papa Benedicto XIII y al rey Felipe V, este último firmado y fechado en 1730; así mismo las figuras de los cuatro evangelistas pintados el 30 de agosto de 1714 para la Capilla de Jesús Nazareno en la Iglesia de La Merced ${ }^{27}$.

Cabe destacar que si bien en el siglo XVII se llevaron a la estampa varios de los monumentos efímeros funerarios levantados en la Catedral limeña a las honras de la reinas Margarita de Austria, 1613; Isabel de Borbón en 1645, y Mariana de Austria en 1697, así como el monumento del rey Felipe IV en 1666, será en el siglo que nos ocupa que este tema iconográfico alcanza su mayor ejercicio.

Iniciaremos la serie dieciochesca con el grabado del túmulo funerario de Carlos II, último rey de la dinastía Austria en España, levantado en la Catedral de Lima y llevado a la estampa por Adame para ilustrar el libro de la relación de sus exequias salido de la imprenta de Contreras en $1701^{28}$. En el ejemplar del jesuita José de Buendía ubicado en la Biblioteca Nacional del Perú se pudo apreciar la existencia do ires è statimas unacen leanteportada y dos en el interior del libro, a la que se şmé másedelantedálámina $69 n$ el túmulo, separada del libro y conservada suelta en la caja fuerte ${ }^{29}$.

En la anteportada del libro de Buendía se representa el busto del monarca Carlos II con el toisón de oro, enmarcado con guirnalda de laureles y dos angelotes que sostienen, uno la corona y el otro el escudo del rey; al centro, el globo terráqueo flanqueado por cuatro figuras alegóricas correspondientes a cuatro continentes: Africa, Europa, América y Asia. A la derecha del grabado la alegoría de Africa representada por un hombre negro, de pie, semidesnudo con turbante, acompañado de un lagarto, junto a él Europa en la figura de una mujer

\footnotetext{
2o Harth-terré. Emilio, Op. cit., p. 65.

27 Vargas Ugarte, Rubén, Op. cit, p. 287.

26 Buendía. José de, Parentación Real... Carlos II... Lima, 1701.

29 Estabridis Cárdenas, Ricardo, Op. cit., p. 273.
} 
sentada sobre un toro enjugándose las lágrimas. A la izquierda, América en la figura de un indígena de pie con faldellín y corona de plumas; a su lado y en la misma posición que Europa, completando el balance simétrico de toda la estampa, Asia en la figura de un hombre con vestimenta oriental, turbante y vara rematados en media luna.

En las páginas 148 y 148 vuelta, el libro de Buendía nos alcanza dos láminas pequeñas pero importantes como documentación, ya que en ellas se aprecia el interior de una imprenta de la época. La imprenta es la de José de Contreras quien participa en estas exequias no sólo como impresor, sino además como poeta, ya que las láminas ilustran un soneto de su inspiración dedicado al monarca. En uno de los grabados se representa a Contreras entregando su soneto al impresor, y en el otro el momento de la impresión de unos corazones con el nombre del rey.

El túmulo levantado en Lima para honrar la memoria del rey Carlos II, fue encargado en $1700 \mathrm{al} \mathrm{mitsmo} \mathrm{arquitecto} \mathrm{que} \mathrm{hizo} \mathrm{el} \mathrm{túmulo} \mathrm{de} \mathrm{su} \mathrm{madre,}$ Mariana de Austria (fallecida en 1696), el fraile mercedario Cristóbal Caballero, a quien Buendía en su libro halaga con las siguientes palabras: «sobre la gracia y talento que tiene para el púlpito añade el magisterio del compás».

El grabado del monumento efímero de Fray Cristóbal Caballero se perennizó gracias a la estampa grabada por Adame (Lám.4), y a la descripción detallada que de él nos alcanza Buendía a partır de la página 39 de su libro:

«En las esquinas del basamento dos pirámides. El primer cuerpo está formado por 16 columnas de 18 pies de largo y 2 de ancho, vestidas con los adornos corintios de estrías, ménsulas, paños y tarjas y en sus capiteles las galas de bozeletes frisos y collarinos. Formó la planta cinco quadros perfectos, uno en el centro y quatro en los ángulos, en que el arte empleó los primores del orden compuesto dejándose servir de los demás; adornáronle de arquitraves frisos, paflones y coronas. Sobre los macizos de las columnas interiores comenzaban a moverse los principales arcos a cada lado en que volaban quatro bóvedas entre quarteles o paños vestidas de hermosas tarjas de jeroglíficos, dexando en medio un crucero o quadro, cuyo cielo entre bien labrados artezones tenía por alma, y empresa un pelícano hiriéndose el pecho con el pico, por sustentar con su sangre a sus polluelos......». 
«Sustentaban esta figura cuatro paños o cuarteles dehermosas tarjas con cuatro jeroglíficos alusivos a la Religión y Piedad del Rey. En el primero se ofrecía un ara con el sacrificio de un cordero...».

«Servían también las cornisas de los cuatro ángulos de impostas al macizo de donde nacían los arcos que eran de punto entero y abrían de boca 16 pies geométricos y 9 de diámetro, quedando todo el pórtico en proporción dupla. Ceñía el medio círculo del arco desde el punto en que cogía el vuelo hasta donde se paraba, una zona o faja de media vara de grueso...».

Se refiere a las roscas de los arcos que tenían inscripciones; la que miraba al coro y que aparece en el grabado decía:

"Lima pesar Denter Carolo post data parentat. MDCLLI».

"Unos y otros versos dejaban entre la clave del arco y la mitad del friso y cornisa bastante espacio para los cuatro escudos de las Armas Reales enteras de dos yaras en alto que se pusieron en medio... Sobre cuya circunferencia (enjutas) se recostaban valientes imágenes, pinturas de cuerpo entero de las virtudes... La justicia y la Fortaleza en el frente principal yeen los colaterales se veía la Prudencia y la Templanza, la Castidad y la Clemencia, la Piedad y la Paz, de tan valiente y airoșopingeliquepareciánđallascon movimiento y solo les faltaba la yoz para persuadir que eran wiogas».

En el grabado es posible ver las dos primeras virtudes.

«Las cuatro bóvedas de los arcos también con pinturas, la del frente con Ganímedes sobre un águila arrebatado de la tierra a servir la copa de Júpiter en el cielo. En otra Prometeo subiendo al cielo con una antorcha en la mano...».

«En los 4 ángulos colaterales se levantan en su centro cuatro pedestalones de 5 pies de alto que adornaban varias marioletas en que estuvieron de pie todo el tiempo de los sagrados oficios, la tarde de la vigilia y mañana siguiente a la missa, los 4 reyes de armas vestidos de luto, falda larga hasta el suelo y con las gramallas de damasco carmesí gravadas de las armas reales con la diversidad de colores que las distinguen orladas de oro, puestas sobre los pechos, 
espaldas y los dos lados», "Los cielos de estos ángulos también iban pintados con 4 tarjas con jeroglíficos».

«Coronaban la cornisa la obra superior de este primer cuerpo ciñiendo el ángulo de en medio y los quatro colaterales con una varanda hermosa de balaustres en el que se colocó el crecido numero de antorchas y en las cuatro esquinas sobre los macizos de las columnas de afuera se llevaron sobre sus pedestales 4 estatuas de bulto entero de las cuatro partes del mundo en que dilata sus dominios la monarquía española. Europa con vestiduras reales, corona y cetro, América desnuda de medio cuerpo para arriba, color tostado, Mascapachac o corona de plumas negras y amarillas en la cabeza embrazando el arco y pendiente del hombro el carcaj de las saetas. Estas miraban al coro en los dos ángulos de la primera parte. En los otros descollaba la Asia con ropaje precioso y turbante en la cabeza».

«Africa color adusto, desnuda medio cuerpo, corona en las sienes y la cornucopia al hombro».

En el grabado Adame colocó estas dos últimas también en el frente y se pueden apreciar. Más adelante Buendia en la página 52 vuelta inicia la descripción del segundo cuerpo del túmulo:

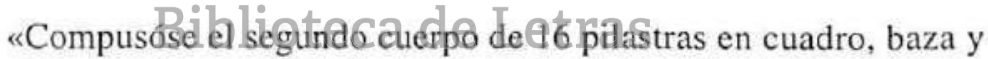
plinto, en dōscanatelestås gallảscorintias de ménsulas bozeletes y frisos, filetes, cornisamiento. Todo este cuerpo servía de imposta al hermoso vuelo de $4 \operatorname{arcos}$........ En las claves de los cuatro arcos las armas reales de Castilla y León talladas en galantes escudos».

«En los cuatro ángulos en pedestalones 4 simulacros de las virtudes; $\mathrm{Fe}$, vendados los ojos, la Esperanza con su ancla y una ave en la mano forcejeando por volar. La Caridad ostentando sus pechos para alimentar a sus hijos. La Religión con tiara, cáliz y cruz pontifical».

Adame sólo presenta a la Esperanza y la Religión en su grabado.

«En el interior de este segundo cuerpo 2 mundos que sustentaban la corona real. Dos estatuas de dos matronas con ademanes y significaciones de grave sentimiento estavan a los lados de uno y otro mundo que las daban a conocer una inscripción en latín que decía: Madrid 
llora, Lima marchita y triste. El cielo de este segundo cuerpo con la pintura del Carro del Sol precipitándose al ocaso.»

«El tercer cuerpo cubo con balaustres y 4 agujas en las esquinas y al centro la esfera de una cupula sobre la que se asentaba un pedestal con sus quadros y perfiles, paflón y corona en que se construía de ramas de olivo y palmas envestidas de fuego la fragante pira en que un fénix batiendo las alas para recrear su incendio y quemar sus plumas se veía arder en la hoguera y espirar en la pira, seguro como lo daba a entender el rótulo que cogía el vuelo de la una a la otra en distancia de 4 varas con las palabras del santo Job, Cap. 29. ..... de que perdiendo con la muerte los días de la vida, multiplicaría mejores días en la eternidad».

«Esta ave singular de Oriente se eligió para el ocaso de N. Augusto Carlos, no menos singular en sus virtudes, que el fénix, y en ser único y morir sin hijos, aunque no sin sucesor ni heredero, pues de las reliquias de su inspiración se anima quien lo sucede, otro galante fénix de juveniles plumas...»?

Hemos querido hacer la transcripción de estos pasajes, ya que en el grabado no es posible apreciar todo el programa iconográfico, que consideramos un importante ejemplo del espíritu de la época y de como se desarrollaban en el arte barroco peruano al igual que en Europa ese mundo de las alegorías, jeroglíficos y emblemas, donde se entremezclabani alegorias efistianas con temas de la mitología clásica, en gran derroche de erudición.

\section{Fray Miguel Adame y el túmulo del papa Benedicto XIII}

En las Adiciones a La imprenta en Lima, Graciela Araujo Espinoza ${ }^{30}$ cita el libro de Alonso del Río: Fúnebre / Religiosa pompa / a Nuestro Santíssimo Padre Benedicto XIII... Oración Fúnebre..., salido de la imprenta de Juan José Cossío en 1731. Asimismo menciona una lámina plegada sobre una alegoría del tema, sin ، tar al autor. Hemos podido localizar dicho libro en una colección particul $\cdots$ limeña y ver la lámina grabada donde se representa el túmulo

to Araujo Espinoza, Graciela, "Adiciones a La Imprenta en Lima (1584-1824)". Fénix, No 8, Lima. 1954, pp. 434-704. 
funerario levantado para las exequias de dicho papa por mandato del $\mathrm{M}$. R.P.M.F. Pedro Benegas, prior del Convento del Rosario de Lima; asimismo la firma del grabador dominico Miguel Adame (Lám. 5).

En la estampa podemos apreciar un túmulo de tres cuerpos, sostenido por columnas de capitel compuesto ornadas en su fuste con cabezas y paños colgantes con frutos, además de símbolos de dignidades eclesiásticas y la calavera de la muerte. La figura orante del Papa se colocó en el segundo cuerpo flanqueada por ángeles y por las alegorías de los cuatro continentes. En el tercer cuerpo y ático, figuras alegóricas de virtudes como la Fortaleza y la Justicia, entre otras. En líneas generales es posible afirmar que en este diseño se rompe con el tradicional túmulo turriforme.

Lorene Pouncey cita el grabado del túmulo en referencia ${ }^{31}$ y dice que fue diseñado por Fray Pedro Benegas, Prior del Convento del Rosario y que el grabado es de Fr. Alamo.

\section{Juan José Espinoza y los túmulos de Luis I y Francisco Farnese, duque de Parma}

Otros de los grabadores documentados en Lima en la primera mitad del

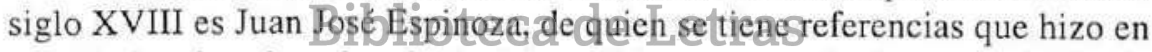
una lámina de cobre el grabadg del catafalco que para las honras del hijo de Felipe V, Luis I, se levanto en la Catedral de Lima en el año de 1725 (no localizado).

$\mathrm{Al}$ igual que Adame, Espinoza trabaja ilustrando obras de don Pedro Peralta Barnuevo, tal como el libro Fúnebre pompa... Francisco Farnese, Duque de Parma..., publicada en 1728. En dicho libro ubicamos el grabado del túmulo que se levantó en la Catedral de Lima con motivo de sus exequias ${ }^{32}$ (Lám.6).

Según refiere el autor del libro, para la erección del túmulo que se levantó en la Catedral por las exequias del duque de Parma, se escogió al arquitecto Manuel Sánchez, a quien califica como perito arquitecto y lo alaba al mencio-

Pouncey, Lorene, Op. cit., p. 27.

12. Peralta Barnuevo, Pedro, Fínebre Pompa... Francisco Farnese, Duque de Parma... Lima, 1728. 
nar que fue el monumento más grandioso que se vio en el templo metropolitano, con una altura de 74 pies castellanos, y con una base que tenía 30 pies de lado. El túmulo estaba compuesto de tres cuerpos; en el centro de los dos primeros se apreciaba el túmulo propiamente dicho y la estatua del difunto y en el último se dibujaron sus armas. La solemne ceremonia se celebró el 8 de mayo con asistencia del virrey marqués de Castellfuerte.

La estampa del túmulo, levantado por el arquitecto Manuel Sánchez, fue grabada por Juan José Espinoza, según la firma que hemos podido apreciar en el ángulo inferior de la lámina. Vargas Ugarte hace la siguiente cita sobre él:

«el 26 de febrero de 1728 se le encomendó la pintura del túmulo que había de erigirse en la Catedral de Lima, con motivo de las exequias del Duque de Parma» ${ }^{33}$.

$\mathrm{Al}$ parecer se refiere a la obra que nos ocupa, con error en la técnica empleada.

$\mathrm{Al}$ observar el grabado del lúmulo en referencia, éste difiere en parte a la descripción de Peralta; en la estampa vemos un túmulo de dos cuerpos y no tres, con columnas de capitel compuesto de fuste decorado con cabezas y paños colgantes, ya arcaizantes para la época, las que sostienen arcos escarzanos. En el primer cuerpo se aprecia el catafalco flanqueado por pirámides de luces y coronado por el escudo de España. Efret segundo-cuerpe se colocaron figuras

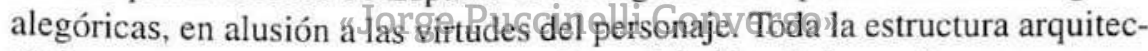
tónica remata en un cupulín con escudo y pirámides de luces. Aunque no aparecen en el grabado, se cita en el documento que en el segundo cuerpo se colocaron las esculturas de Pedro Luis Farnese, Alejandro Farnese, Octavio Farnese y Ranucio Farnese, ilustres antepasados del Duque de Parma.

\section{Juan Francisco Rosa y el túmulo del arzobispo Diego Morcillo Rubio de Auñón}

La figura del grabador Juan Francisco Rosa, está documentada a través de sus obras firmadas entre 1739 y 1746 . En base a ellas se puede determinar que

3 Vargas Ugarte, Rubén, Op. cit., p. 348. 
su producción calcográfica, principalmente giró en torno a la estampa religiosa; sin embargo no está ausente en ella el tema de la arquitectura funeraria efímera.

En 1743, Fray Alonso del Río Salazar y Figueroa publica: Magnífica parentación y fúnebre pompa en la ocasión de trasladarse de la sepultura de los señores arzobispos al sepulcro y monumento que se erigió en la capilla de la Purísima Concepción de la Catedral. En dicha edición se incluyó el grabado del túmulo del Arzobispo Diego Morcillo Rubio de Auñón, firmada por Juan Francisco Rosa, estampa que hemos podido apreciar a través de una publicación de Lorene Pouncey ${ }^{34}$ donde aparece un túmulo muy particular en forma de pirámide truncada escalonada, pintado con elementos de follaje y símbolos eclesiásticos e iluminado con infinidad de achones con cirios en cada escalinata, y en el remate de la pirámide un lecho bajo dosel.

\section{El túmulo del rey Felipe $V$}

Una de las obras anónimas importantes que cierran la primera mitad del siglo XVIII es el grabado del túmulo del rey Felipe V, hecho en 1748 para el libro de Miguel Sainz de Valdivieso y Torrejón. Aunque el ejemplar consultado en la Biblioteca Nacional de Lima no conserva la lámina con el túmulo, el texto que lo describe da fe de su ejecución:

«Pero porque tan bella obra depesitada como pensamiento en la razón, no quedasse expuesta al diferente arbitrio de la idea, se procuró imitar en breve lamina: cuya estampa, o fuesse otra descripción para los ojos: o del mismo túmulo perpetuo monumento ${ }^{35}$.

En sus líneas elegíacas Sainz se remonta a Egipto y a la antig,edad clásica y hace una apología de la arquitectura efímera en honor de los monarcas españoles. Nos informa que el edificio era de tres cuerpos en orden corintio, que poseía esculturas alegóricas como las de la Justicia y la Fortaleza y hace una descripción detallada de los elementos arquitectónicos en el lírico y confuso lenguaje de la época.

34 Pouncey, Lorene, Op. cit. p. 29.

35 Sainz de Valdivieso y Torrejón, Miguel de, Parentación Real... Felipe V.... Lima, 1748, p. 18. 


\section{José Vázquez y el túmulo de la reina madre Isabel Farnesio}

Entre todos los grabadores hasta ahora documentados en la Ciudad de los Reyes, sin lugar a dudas, José Vázquez es el más destacado. Su producción supera en riqueza iconográfica a todos los grabadores coloniales, como lo demuestra la miscelánea de sus creaciones que abarcan: retratos, túmulos, estampas y monumentos religiosos, mapas, planos y hasta diseños de ingeniería bélica. Entre esta variedad sus retratos son la mejor carta de presentación.

Gracias a la documentación obtenida a través de las ilustraciones en los libros de la época y de las estampas sueltas, se puede trazar un perfil del desarrollo plástico de Vázquez entre los años de 1759 y 1794, treintiséis años de actividad casi ininterrumpida.

El primer túmulo funerario llevado a la estampa por nuestro artista data de 1768 y corresponde al de la Reina Madre doña Isabel Farnesio, segunda esposa del Rey Felipe V de España, incluida en el libro de José Antonio Borda y Oros $\mathrm{CO}^{36}$, editado en la Imprenta Realde la Calle del Palacio por Nicolás Urdín y Cevallos.

\section{José Vázquez y el túmulo del papa Clemente XIV}

Graciela Araujo ${ }^{3}$ cita una lámina def eatafâtco levantado en la iglesia de

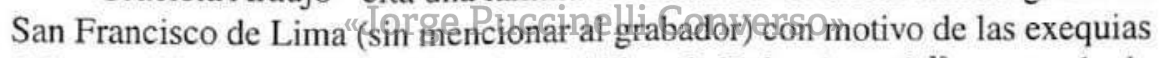
del papa Clemente XIV, publicada en el libro de Delso Agustín ${ }^{38}$ encargado de la relación de dichas exequias. Al revisar este libro localizamos otra obra de Vázquez, ya que el grabado del túmulo del papa lleva su rúbrica.

A la muerte del papa Clemente XIV el rey Carlos III por real cédula mandó que en todas las iglesias de los reinos de las Indias se celebraran solemnes exequias en honor a él. La Catedral fue la primera en realizarlas, seguida por otras iglesias como la de San Francisco, donde el día 26 de agosto de 1775, se lloró la muerte del quinto de sus pontífices.

\footnotetext{
Borda y Orosco, José Antonio, Relación reales exequias... Isahel Famesio. Lima, 1768.

Araujo, G., Op. cit.

Delso, Agustin, Relaciön de las exequias... Clemente XIV. Lima, 1776.
} 
Según la descripción de Delso Agustín el túmulo respondía a las siguientes características:

«Erigieron sobre el arco del presbiterio un magnífico túmulo de sesenta pies castellanos de alto, organizado según todos los primores del orden compuesto, y añadido de aquellos adornos, que repartidos por una mano sobria hacen resaltar las bellezas de la arquitectura y no la confunden».

«El primer cuerpo que tenía diecinueve pies dejaba ver en su centro bajo un hermoso dosel de terciopelo negro galoneado en oro, dos almohadas cubiertas de lo mismo, sobre las quales estaban la tiara y cruz pontifical como insignias de dignidad del objeto Difunto». «En las dos columnas principales se pusieron dos vistosas tarjas, que en diversos idiomas significaban el dolor de la Religión de San Francisco en la muerte del quinto de sus pontífices».

«En el segundo cuerpo de trece pies contenía dentro de su frente principal una estatua del Pontífice difunto de rodillas ante Cristo». «En los vacíos colaterales de este cuerpo se colocaron insignias de su Santidad como el hábito de su profesión, el sombrero de Cardenal y el roquete y bonete pontificio», «Las dos columnas que dividían el fondo principal del octógono también con tarjas».

"Los dos eưerpos restantes guạardabancensaltura y demás dimensiones aquella decadencia progresiva que manda el Arte».

«En el espacio que dejaban entre sí las columnas del tercer cuerpo, se registraban las vestiduras sacerdotales y sobre ella puesta una mitra".

«Dentro del cuarto cuerpo que se formaba de un hermoso frontispicio se adoraba en competente bulto la imagen de Cristo Cruficicado». «Los lados del frontispicio estrivan sobre dos pedestales que hacían respaldo a las tarjas que correspondieron a este cuerpo». «Coronábalo y era el remate de toda la fábrica un escudo de seis pies de altura en que estavan grabadas las armas de la Religión de San Francisco».

«Recibía el túmulo una nueva hermosura sobre la de su fábrica del crecido número de luces que ardían en sus barandas en sus pirámi- 
des y en muchas arañas de plata que pendían de las cornisas de todos los cuerpos».

José Vázquez y los túmulos de los arzobispos Pedro Antonio de Barroeta y Angel y Diego Antonio de Parada

El siglo XVIII trae como innovación que al igual como se celebraban exequias por reyes, se hicieron también por papas, arzobispos y otros personajes ilustres; aparte de las celebradas por el papa Clemente XIV, sirven de ejemplo dos obras ubicadas de José Vázquez con grabados de los túmulos de los Arzobispos Pedro Antonio de Barroeta y Angel y Diego Antonio de Parada.

El grabado del túmulo del arzobispo Pedro Antonio de Barroeta y Angel ilustra el libro de sus exequias escrito por Joseph Potau, en 1776, Abogado de la Real Audiencia y cura Rector de la Parroquia de San Sebastián de Lima ${ }^{30}$ (Lám.7), editado en la imprenta de los Niños Huérfanos en Lima, en tiempos del Virrey Amat. La lámina está firmada: Joseph Vázquez Sculp Año de 1776. En ella es posible apreciar la magnificencia del túmulo compuesto de dos cuerpos y ático, sobre plataformas escalonadas entre dos pirámides de luces. En el cuerpo principal se ve el catafalco con los atributos episcopales, flanqueado por cuatro figuras alegóricas que exaltan las virtudes del difunto. En el segundo cuerpo, bajo cupulín, lamuenteqepresentátâpor ûn esqueleto con arco y flecha y cuatro figuras alegórichas dedahte cdeilas dỏlumnașademás de otras dos exentas que representan a la Esperanza y la Caridad. Corona la estructura arquitectónica la alegoría de la Iglesia.

El segundo grabado de un túmulo arzobispal firmado por Vázquez, ilustra el libro de la relación de las exequias del arzobispo de Lima don Diego Antonio de Parada, escrita por Alphonso Pinto y Quesada, Abogado de la Real Audiencia y Prior del Santo Oficio ${ }^{40}$ (Lám.8), libro editado en Lima por la imprenta de los Niños Huérfanos. En esta relación figura también, aparte del grabado del túmulo, un grabado con el retrato del arzobispo. La lámina del túmulo se

\footnotetext{
99. Potau. Joseph, Lagrimas de Lima en las exequias del llmo. Sr. de D. Pedro Antonio de Barnota y Angel. Lima, 1776.

40 Pinto y Quesada. Alphonso, Relación de las exequias del Arzobispo de Lima D. Diego Antonio de Parada. Lima, 1781.
} 
encuentra casi al centro del libro y es seguida por páginas que mencionan epigramas en latín, que estaban al pie de las estatuas de las virtudes: «Fides, Spes, Charitas, Justitia, Prudentia, Fortitudo, Temperantia». Asimismo se puede leer que las tarjas que adornaban el túmulo y columnas inmediatas contenían poesías: «Epitaphium, Aliud, Epigramma acrosthicum», etc. Al igual que el retrato, la estampa del túmulo está firmada: Joseph Vázquez Sculp. Li. Año de 1781.

En base a la estampa de la arquitectura efímera que se levantara en la Catedral para el arzobispo De Parada, podemos decir que el túmulo estaba compuesto de tres cuerpos, flanqueados por pirámides de luces y sostenidos por columnas con decoraciones de rocallas. El primer cuerpo con planta quebrada decorada con rombos y sostenido por cuatro columnas con decoración de rocalla, alberga en su interior el catafalco. El segundo cuerpo es de menor escala y posee cuatro columnas de fuste liso, a las que se adosan alegorías de las virtudes, y en la calle central la figura de la muerte en forma de esqueleto alado con arco y flecha. El tercer cuerpo, en decreciente y similar a la anterior con figuras alegóricas adosadas a las columnas, y en su interior una mesa con dignidades episcopales. Por último en el remate la afegor a de la Iglesia, con tiara, cruz papal y eucaristía.

$\mathrm{Al}$ parecer, por la semejanza en algunos elementos entre ambos túmulos, creemos que la arquitectura efímera del túmulo del Arzobispo Barroeta se reutilizó con las variapyes sanotadascen lał exēquias debarzobispo Antonio de Parada.

\section{"Jorge Puccinelli Converso"}

\section{José Vázquez y el túmulo de Carlos III}

Las reales exequias oficiales por la muerte de Carlos III las mandó celebrar el virrey Teodoro Croix y fueron publicadas en el libro de Juan Rico ${ }^{41}$, libro editado en la imprenta de Niños Expósitos. Para dicha publicación Vázquez llevó a la estampa el túmulo levantado en la Catedral de Lima por Francisco de Ontañón, ensamblador activo en la Ciudad de los Reyes a fines del siglo $\mathrm{XVIII}^{42}$ (Lám.9). El grabado lleva la firma: Vázquez Sculp año 1789, quien a través de él perennizó un magnífico túmulo.

\footnotetext{
4 Rico, Juan, Reales exequias... Carlos III... Lima, 1789.

4 Vargas Ugarte, Rubén, Op. cit., p. 330
} 
La arquitectura efímera levantada en la Catedral de Lima en las honras fúnebres de Carlos III responde del modelo turriforme, dentro de la tipología que viene desde el siglo XVII, pero ya decorado con elementos de rocallas en los arcos mixtilíneos de sus tres cuerpos y en las enormes pirámides de luces. Como se acostumbraba para este tipo de arquitectura se incluyen figuras alegóricas. En el primer cuerpo es posible distinguir, delante de las columnas, las alegorías de la Fe, la Caridad y la Fortaleza, a ambos lados del catafalco donde se ubican las armas reales. En el segundo cuerpo y en el remate del tercero es posible apreciar alegorías de los reinos del dominio de la corona española. Al centro del tercer cuerpo llama la atención la alegoría de la muerte representada por un esqueleto con arco y flecha, figura que nos remite a la que presentan los túmulos de los arzobispos Pedro A. de Barroeta y Diego A. de Parada estudiados líneas atrás, grabados también por Vázquez y que permite suponer que es aquella escultura de la muerte o «Arquero de la Muerte», como también se le conoce a la obra que se conserva en el convento de San Agustín de Lima, realizada por el escultor limeño Baltazar Gavilán ${ }^{43}$. Todo el aparato remata en una alegoría de la Fama de pie sobre el globo terráqueo, con el escudo de Lima enmarcado en tarja de rocalla; su brazo izquierdo en alto y sus vestiduras agitadas al viento le dan a la figura una dinámica barroca.

\section{Las exequias de Carlosithlien te Eniversidad de San Marcos}

Aunque no se tieneconocimfento de la fealizacion de algún túmulo levantado en las exequias que se celebraron en la Universidad de San Marcos por la muerte de Carlos III, como dato referencial deseamos anotar que en 1789 se publicó en Lima el libro de don José Durán ${ }^{44}$, Catedrático de Prima de Teología Moral de la Universidad de San Marcos, quien da cuenta de dichas exequias en la edición de la imprenta de la Casa Real de Niños Expósitos, En este libro no se hace mención a túmulo levantado en dicha casa de estudios, sin embargo si posee un grabado con el retrato del rey, firmado por Vázquez. Asimismo Durán nos informa en su libro que se pintó a la diosa Minerva sentada llorando en la rivera del río Rímac, y junto a ella una de las ninfas cantando, por entretener el dolor de la muerte de Carlos III.

43 Gjurinovic Canevaro, Pedro, "La escultura de la muerten, El Comercio, 22 de abril de 1981, p. 2.

« Durán. José, Oración Finébre... celébró la Real Universidad de San Marcos... Carlos III... Lima, 1790. 


\section{Las exequias de Carlos III en el Cusco}

Al igual que el libro de Durán citado líneas atrás, hemos podido localizar un libro de Ignacio de Castro ${ }^{45}$, rector del Real Colegio de San Bernardo del Cusco y Cura de la Parroquia de San Jerónimo de la misma ciudad, en el cual tampoco se da cuenta de algún túmulo levantado por Carlos III en dicha ciudad, sin embargo constituye una manifestación de las fiestas luctuosas en otras ciudades fuera de la capital del Virreinato.

Creemos que el desarrollo del grabado en Lima en la época de Vázquez, está íntimamente relacionado con ese momento de esplendor del grabado que constituyó la segunda mitad del siglo XVIII para España. Ya en tiempos del segundo reinado de Felipe V se funda la Real Academia de San Fernando (1744), que será inaugurada solemnemente en el reinado de Fernando VI (1752). En dicha Academia se incluyó también la enseñanza del grabado, producto de la nueva política del proteccionismo oficial al grabado ilustrado.

Fray Antonio de Contreras y el túmulo de Mariana Josefa de Austria

En la segunda mitad del siglo XVIII encontramos activo al fraile mercedario Antonio de Contreras, autor del grabado del túmulo de la Reina Viuda de Portugal doña Măriana Josefa de Austria ${ }^{46,27}$. La relación de las exequias de la Reina fue llevada a 1 imprenta por fray Alexo de Alvites, de la Orden de San Francisco ${ }^{48}$. Estas exequías se realizaron gracias al celo de don José Manso de Velasco del Orden de Santiago, Conde de Superunda... Virrey Gobernador y Capitán general de los Reinos de Perú y Chile.

Con la finalidad de tener una idea aproximada de la magnificencia de la arquitectura efímera levantada con motivo de estas exequias, (ya que hasta la fecha no se ha ubicado el grabado que la ilustró) es que nos detendremos en la página 30 del libro de Alvites donde se inicia su descripción:

45 Castro, Ignacio de, Relación de las Reales exequias... a Carlos III... Cusco, 1789.

46 Medina, José Toribio, Op. cit., p. 479

47 Vargas Ugarte, Rubén, Op. cit., p. 302

48 Alvites, Alexo de, Puntual descripción / fúnebre lamento / y sumptuoso túmulo /... Doña Mariana Josepha de Austria... Lima, 1756. 
«La construcción de túmulos magníficos tuvo un primer origen en la errada imaginación de los Egipcios, continuóse loca vanidad de los romanos y se conserva religiosa constumbre entre los católicos». "Son estos unas memorias del olvido donde se adora la majestad en sus cenizas, y se guarda la grandeza en la figura». "Son el Palacio donde vive el nombre de los héroes para desengaño y para exemplo...». «El que levantó a la difunta Reyna fue proporcionado a la grandeza del Objeto y a la exhorbitancia del dolor».

"La iglesia catedral arruinada en el temblor del 28 de octubre (cuando Júpiter despide el rayo no exceptúa de la llama ni aún a su templo). Se admira hoy en gran parte restituída...».

«En la Nao principal, por el extremo que mira azia el Oriente se fabricó el Regio Túmulo. Era su arquitectura del orden compuesto o italiano. Su figura exagonal con tres aspectos, vestidos de hermosura y majestad».

«Sobre un Soccolo de un pie se levantó un pedestal de quatro con su cordón, listoncillo, gola y filete. Cargaban sobre él seis columnas de 12 pies de elevación cada una con su astrágalo entre dos cordones caulicolo y óvalos debaxo del abaco...». «Sobre los Parastades Postes y chambas de los columnarios se volaron 8 arcos rebajados con sus claros correspondientes. En et centro det arco principal se colocó la tumba sobre ứ paño y cojin de tereibpeforlegro bordado de plata se puso la corona y cetro de oro".

«En los ángulos, sobre pedestal de bara y media asistieron en pie los Reyes de Armas...». «En el espacioso lienzo que servía el respaldo al Camarín se pintó con letras de oro perfilado en negro en Magestuoso epitafio que vestido de las tres formas: Pathitia, Moral, Racionnal, persuadía el dolor...».

«En los ángulos del epitafio se pusieron guarnecidos de Palmas y laureles quatro ovalos, donde se escribió el pinzel otros tantos sonetos sepulcrales, dignos del cedro y el ciprés».

Entre ellos como ejemplo citamos:

«Su nombre aun es María... Austria su vuelo, Viena su cuna. Portugal su trono: su fama el Mundo y su Descanso el cielo». 
En el segundo cuerpo, según la descripción los soportes estaban conformados por seis columnas, adornado con tableros, volutas, arcos y cinco tarjas donde se leían las empresas que declaraban los servicios hechos a la iglesia por la nobilísima casa de Austria. En la primera tarja se pintó un diamante, en la segunda una nave, en la tercera el águila con dos cabezas, en la cuarta un río y en la quinta el firmamento. Este segundo cuerpo remataba en una cúpula de media naranja y estaba flanqueado por pirámides de luces.

Culmina la descripción con las siguientes palabras:

«Fabricado en esta forma el Regio Túmulo se dexo ver proporcionado en sus modelos - robusto en sus pedestales, sólido en sus columnas, sublime en sus arcos...».

\section{José Carlos de Zelada y el túmulo del Obispo Juan de Castañeda Velázquez y Salazar}

Zelada es el único grabador colonial que al lado de su firma escribía que era peruano y además dorador. Su producción ubicada hasta el momento es pequeña y abarca los años que van de 1759 a 1763.

No está ausente en-la producción calcográfica de Zelada el tema de la arquitectura efímera, tal como 80 dernuestra la éstampa del túmulo de las exequias de don Juan de Castañedalvelảzqueż yonverso»

Salazar, Obispo de Panamá y del Cusco, obra que ilustra la relación de las pompas fúnebres del distinguido obispo, mandadas celebrar por don Joaquín de Lamo y Zúñiga, conde de Castañeda y de los Lamos, teniente coronel del Regimiento de la Infantería española de Lima (Lám. 10). En la descripción de la fiesta luctuosa realizada por el doctor don Isidro Joseph Ortega y Pimentel ${ }^{49}$, catedrático de Método en la Real Universidad de San Marcos y dedicada al virrey Amat, se hace un minucioso recuento de dichas exequias. El libro fue impreso en Lima en la oficina de la calle de la Coca, y aparte de la estampa del túmulo registra en las primeras páginas un escudo firmado por Zelada en 1762.

\footnotetext{
4) Ortega y Pimentel, Isidro, Relación de las exequias de D. Juan de Castañeda Velázquez y Salazar... Lima, 1763.
} 
A diferencia de otros libros de fiestas luctuosas citados, no se encuentra en la relación de Ortega y Pimentel la descripción del túmulo del obispo Castañeda, sin embargo el ejemplar ubicado en la biblioteca del Convento de la Recoleta de Arequipa posee aún la lámina con la imagen de la arquitectura efímera levantada en la Catedral Metropolitana. Según este documento gráfico podemos ver que se levantó la obra sobre un alto podio y se desarrolló en dos cuerpos de planta octogonal flanqueados por pirámides de luces. El primero de ellos sostenido por ocho columnas de fuste liso albergaba el catafalco, en el segundo cuerpo a manera de templete con cúpula, se mostraban las dignidades episcopales del difunto, y la alegoría de la muerte en un esqueleto con la guadaña. En el remate destacaba un gran escudo del dignatario eclesiástico.

\section{Camacho y el túmulo de María Bárbara de Portugal}

En el siglo XVIII surge la figura de un grabador del cual se desconoce el nombre, ya que tanto Toribio Medina como Harth-terré sólo lo citan bajo la denominación de "Camacho», tal como aparece la firma en sus grabados. Aún no se tiene información sobre suformación pero deducimos que debió ser buena, ya que sus obras documentadas dan muestra del dominio del buril.

Hemos localizado tres grabados de Camacho que corresponden a las estampas de los monumentos êfîmerosdevantados poelas exequias de la reina doña María Bárbara de Portugạ fechada an (1759 la de su esposo Fernando VI fechada en 1760 y la de doña María Amalia de Sajonia esposa de Carlos III, fechada en 1761, obras cuya autoría arquitectónica recae en Antonio Bexarano Loayza, artífice a quien se le encargaron los monumentos para las fiestas luctuosas en la Catedral de Lima.

La lámina del túmulo de la reina doña María Bárbara de Portugal ilustra el libro de Fray Mariano Luxan ${ }^{50}$, grabado ubicado por Lorene Pouncey en la Biblioteca del Convento de la Recoleta de Arequipa ${ }^{51}$. El túmulo responde a un edificio de tres cuerpos de planta octogonal, dentro del tradicional corte turriforme en decreciente, que como hemos visto en la obra de Vázquez se mantiene hasta bien avanzado el siglo XVIII. Si comparamos el diseño arqui-

\footnotetext{
so Luxán, Fray Mariano, Rélación fúnebre... María Bárbara de Portıtgal... Lima, 1760

4 Pouncey. Lorene, Op. cit. p. 29.
} 
tectónico desarrollado por Bexarano para este túmulo, con el que realizó Francisco de Ontañón para el túmulo del rey Carlos III treinta años después en 1789, encontraremos semejanzas estructurales y de ornamentación.

En el túmulo de María Bárbara de Portugal cada cuerpo lleva ocho columnas de orden dórico que soportan cornisas sobre las que descansan balaustradas, y entre las columnas se forman arcos mixtilíneos a base de elementos de rocalla. En el interior del primer piso detrás del altar se colocó el túmulo con las dignidades reales y en el segundo y tercer cuerpo arañas de luces. La ornamentación principal se dio en las enjutas de los arcos, formados por volutas y elementos de rocalla, asimismo en las enormes pirámides de luces colocadas en cada uno de los cuerpos, rematadas en la torre y el león con cetro y corona, símbolos de la realeza española. Todo el aparato funerario está terminado en gigantesca corona imperial sobre dos mundos.

\section{Camacho y el túmulo de Fernando yI}

La lámina del túmulo del rey Fernando VI ilustra el libro que sobre sus exequias escribiera el padre Juan Antonio Rivera ${ }^{52}$. El túmulo realizado por Bexarano al año siguiente del de la Reina María Bárbara, fue dirigido por el doctor D. Pedro Bravo de Rivero por encargo del virrey Manso de Velasco y descrito por Rivera en eblibo que da cuenta de lazpempa fúnebre, de la siguiente manera: "Jorge Puccinelli Converso"

«En el crucero de la Iglesia se asentó sobre un zócalo de un (1) pie y medio, un quadrado de tres pies de elevación y ciento quarenta y quatro de periferia o circunferencia, con 34 por cada lado. En cada uno de los cuatro ángulos del zócalo se fixó un obelisco de 33 pies de altitud, teniendo seis el pedestal, nueve el jarrón y 18 la aguja. Su color era blanco, entretejido de negro. La base del pedestal en estas pirámides era un cymasio inverso o Gola con molduras muy delicadas, su cornisa se engalana de un collarino, con precioso astrágalo entre el cual, y el arquitrabe estaba el friso, donde se veían bellos triglifos y metopas con aseados follajes".

s2 Rivera. Juan Antonio, Pompa funeral en las exequias del Rey Don Fernando VI... Lima, 1760. 
«Las cuatro agujas remataban en sus cúspides de las cuales dos sostenían un bizarro león sobre dos órbitas con las reales insignias de cetro y corona y las otras dos con un bien hecho castillo».

«Subíase a este basamento por 4 primorosas escalas de 7 gradas y 6 pies de latitud correspondiente a las 4 fachadas del edificio las que se adornaron de pasamanos y barandas con 80 mecheros».

«En este piso elevado, sólido y espacioso zócalo se erigió el Real Túmulo de Orden Dórico, dividióse en 3 cuerpos. La longitud de todo el edificio fue de 6 pies castellanos».

«Contaba el primer cuerpo de 8 columnas, sobre el entablamento, ciento cincuenta balaustres con candilejas con cirios».

«A estas 8 columnas se seguían las Retro-Pilastras, con tal orden, que sobre sus impostass se montaron 4 arcos que hacían las 4 portadas cuyos diámetros eran de 11 piesn.

«El espacio interior de las ocho columnas era un quadro cuyo perímetro tenían 84 pies catellanos de 7 varas por lado sobre el cual iba el pedestal en que se puso la real tumba. Entapizose esta de tercipelo negro orlado con franja de oro y las armas de España bordados y con piedras》iblioteca de Letras «En este primer cuerpo scipuso un altarerson dosel todo de plata».

«El segundo cuerpo tambien de orden dórico y semejante al primero era de 18 pies de elevación. También tenia 4 pirámides de la misma figura, y balaustres sobre el entablamento. Los comedros de las 4 caras con escudos burilados».

En el grabado en lugar de las columnas citadas aparecen pilares cimbreantes que le dan inestabilidad y movimiento.

«El tercer cuerpo con un zócalo de 3 pies de altitud la columna de 7 y de 2 la coronación. Los 4 obeliscos se asemejaban en todo a los del segundo cuerpo como también la costosa baranda de la circunvalación». 
«En la planicie superior se levantó la cúpula sobre ella un abaco o quadrado tablero en cuyo plinto asentaron dos corpulentos mundos, sobre quien descansaba una Imperial corona».

\section{Camacho y el túmulo de María Amalia de Sajonia}

La lámina del túmulo de la reina doña María Amalia de Sajonia, ilustra el libro de Victoriano Cuenca ${ }^{53.54}$ (Lám.11).

A pesar de que según Medina el catafalco del rey Fernando VI se usó al año siguiente para las honras de María Amalia de Sajonia, al comparar las láminas hemos comprobado que guardan en plano general cierta similitud, pero no son los mismos. Ambos están sobre plataformas escalonadas seguidas de un gran edificio de tres cuerpos con columnas de orden dórico, elementos de rocalla, volutas y contravolutas, balaustres y enormes pirámides de luces en las esquinas, rematadas en torres y leones. Bajo el primer cuerpo sobre pedestal, la tumba real y coronándole el escudo correspondiente. A nuestro parecer el de la reina doña María Amalia de Sajonia se aprecia en la lámina más elaborado, su segundo cuerpo es cerrado a manera de templete, con muros ondulantes que soportan una cúpula sobre la cual va un remate derivado del estípite, que cumple la función de pedestal del escudo de Lima, los dos mundos y la corona imperial.

\section{Biblioteca de Letras}

\section{"Jorge Puccinelli Converso»}

Si bien los diseños de los túmulos de Camacho responden en líneas generales al barroco centroeuropeo, es apreciable en ellos, al margen de la ornamentación, ciertas variantes en su estructura arquitectónica que marcan una evolución de la forma turriforme tradicional empleada en el de 1759, a la que sigue un complejo rococó en el de 1760, hasta ciertos aires neoclásicos que se anuncian en el túmulo levantado en 1761.

Es necesario anotar que los tres grabados citados de Camacho ilustran libros editados por la imprenta limeña de Pedro Nolasco Alvarado.

5. Cuenca, Victoriano, Parenación solenme... Doña Maria Amalia de Saxonia... Lima, 1761.

4 Estabridis Cárdenas, Ricardo, Op. cit.. 1984, p. 286. 


\section{LOS GRABADOS DE TUMULOS EN EL SIGLO XIX}

\section{(Epílogo Colonial)}

Dentro de este acápite hemos considerado la producción de grabados desarrollada en los primeros años del siglo XIX dentro del epílogo colonial, periodo en que sobresale una de las figuras más importantes del grabado en el Perú, la de Marcelo Cabello, sobre el cual centraremos nuestra atención.

Marcelo Cabello y el túmulo de arzobispo Juan Domingo Gonzales de la Reguera

Tenemos algunas noticias de sus obras a través de los escritos de Medina, Vargas Ugarte y Harth-terré, a las que sumamos las ubicadas en nuestra búsqueda. A pesar de ello no podemos afirmar que se ha agotado la información sobre su producción que fue muy vasta.

A la fecha podemos afirma que su producción documentada va de 1796 a 1821 y que a lo largo de esos años desarrolla el retrato, la estampa religiosa, planos y túmulos, todavía en la técnica más usada en la colonia, el grabado en cobre.

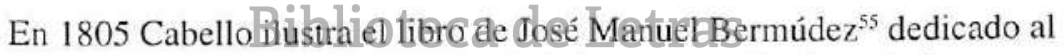
arzobispo D. Juan Dominge Gonzales delackequera egditado en la imprenta Real de los Huérfanos y dedicado a la memoria del XVI1 ${ }^{\circ}$ Arzobispo de Lima.

En una colección particular de Lima se ha podido ubicar el libro de Bermúdez e incluso la plancha de cobre que se utilizó para el retrato. El ejemplar mencionado aún conserva, además del retrato del obispo, el grabado del túmulo que se levantara en la Catedral de Lima (Lám. 12).

El túmulo del arzobispo González de la Reguera en líneas generales responde a los caracteres de la tipología de retablos que se levantaron en Lima en la época de Matías Maestro; consta de dos cuerpos, el primero con las calles laterales orientadas en ángulo hacia la central, sostenido por columnas dóricas de fuste marmóreo que albergan alegorías de la Fe, la Esperanza, la Caridad y la Justicia y al centro la figura orante del difunto. El segundo cuerpo a manera

s. Bermúdez. José Manuel. Fama póstuma del... D. Juran Domingo Gonzales de la Regıtra. Lima, 1805. 
de templete octogonal, ornado igualmente con figuras alegóricas de virtudes, alberga otra escultura del obispo en posición sedente con sus dignidades episcopales, acompañado por figuras alegóricas y por dos ángeles que sostienen un cortinaje que sirve de fondo a todo el monumento funerario. El remate con el escudo del arzobispo, ángeles y la acostumbrada ave fénix, como símbolo de la inmortalidad.

La presente investigación es parte de un trabajo mayor en proceso, donde intentaremos trazar un perfil del desarrollo general del grabado en el Perú. El tema sobre el grabado peruano colonial no está agotado, aún queda camino por recorrer, sirvan estas líneas como una muestra de la riqueza casi inexplorada de la obra de estos artistas plásticos peruanos activos en dichos siglos, quienes al lado de pintores, escultores y arquitectos conforman la historia del arte peruano.

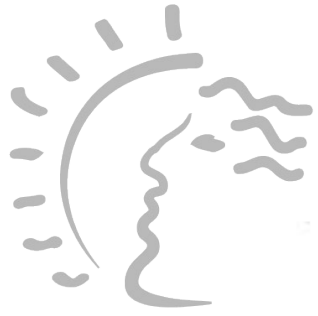

Biblioteca de Letras "Jorge Puccinelli Converso" 


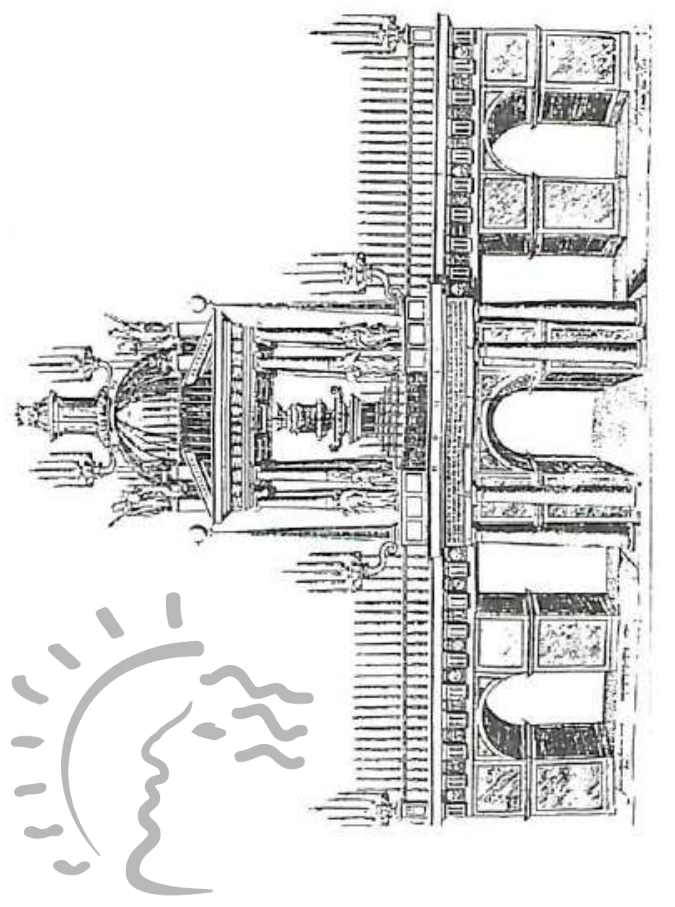



\section{Biblioteca de Letras}

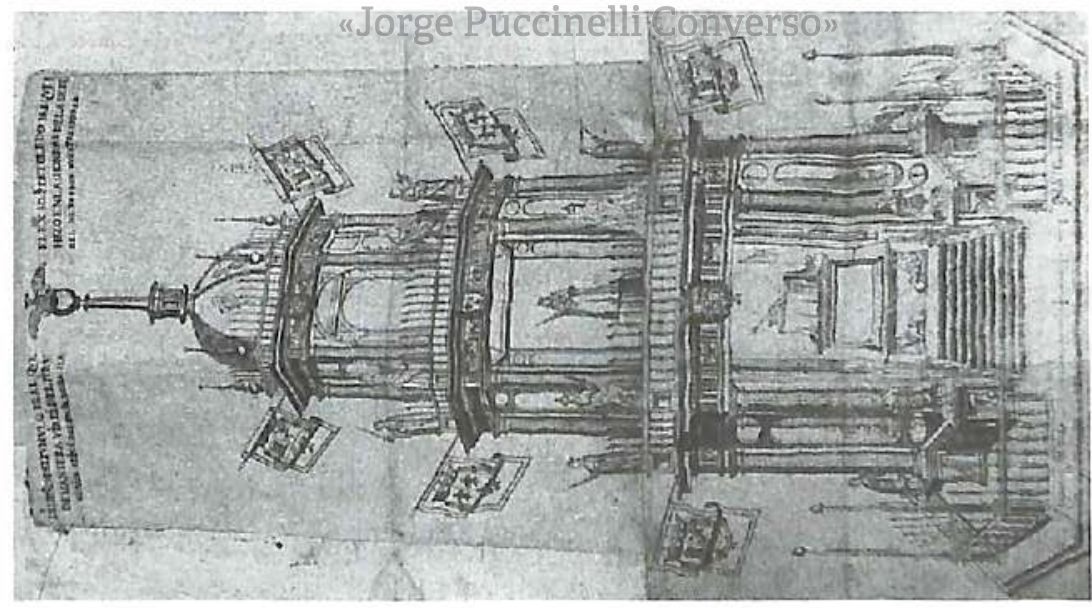

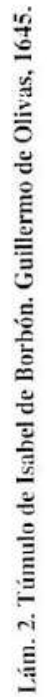



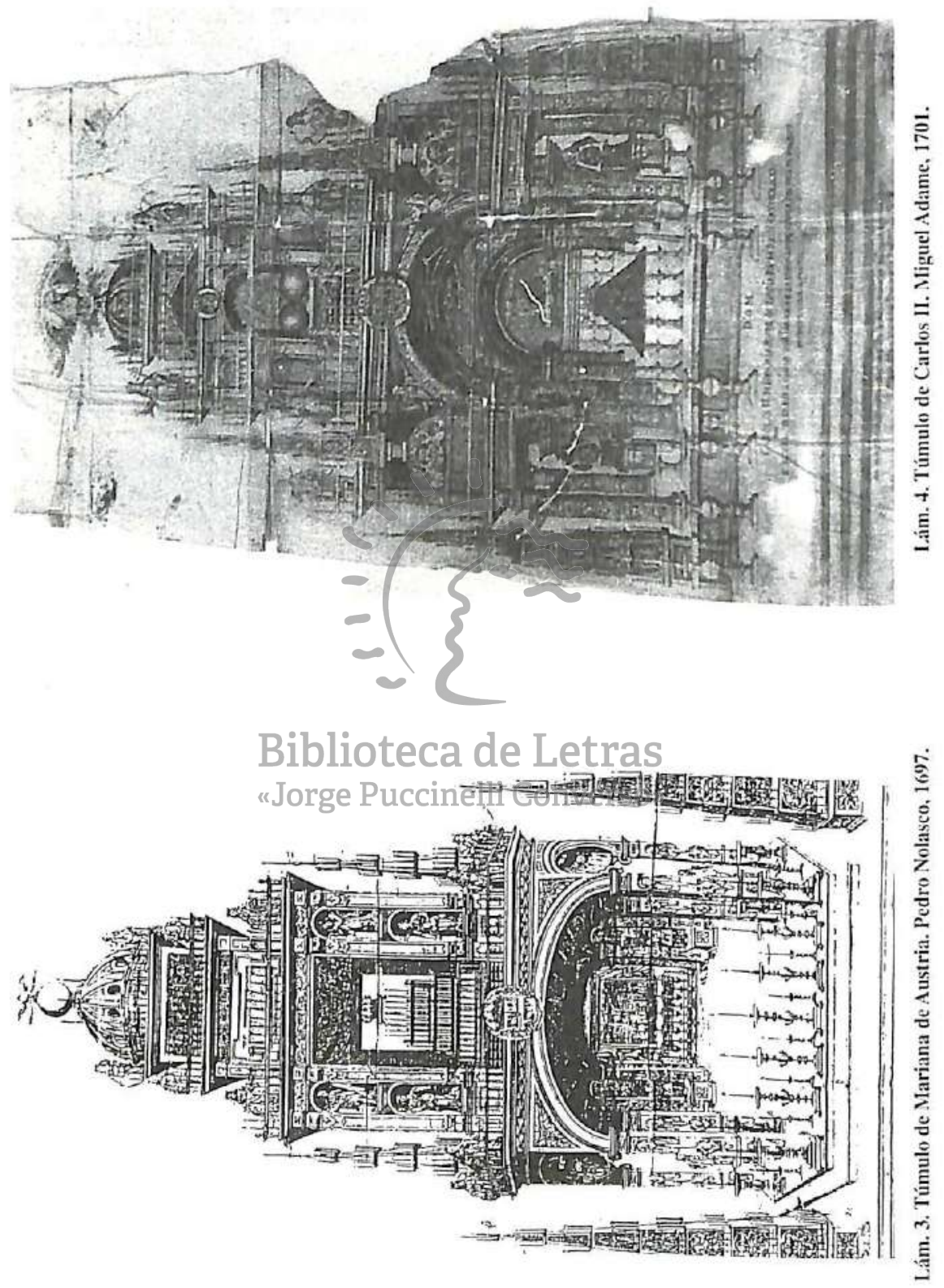

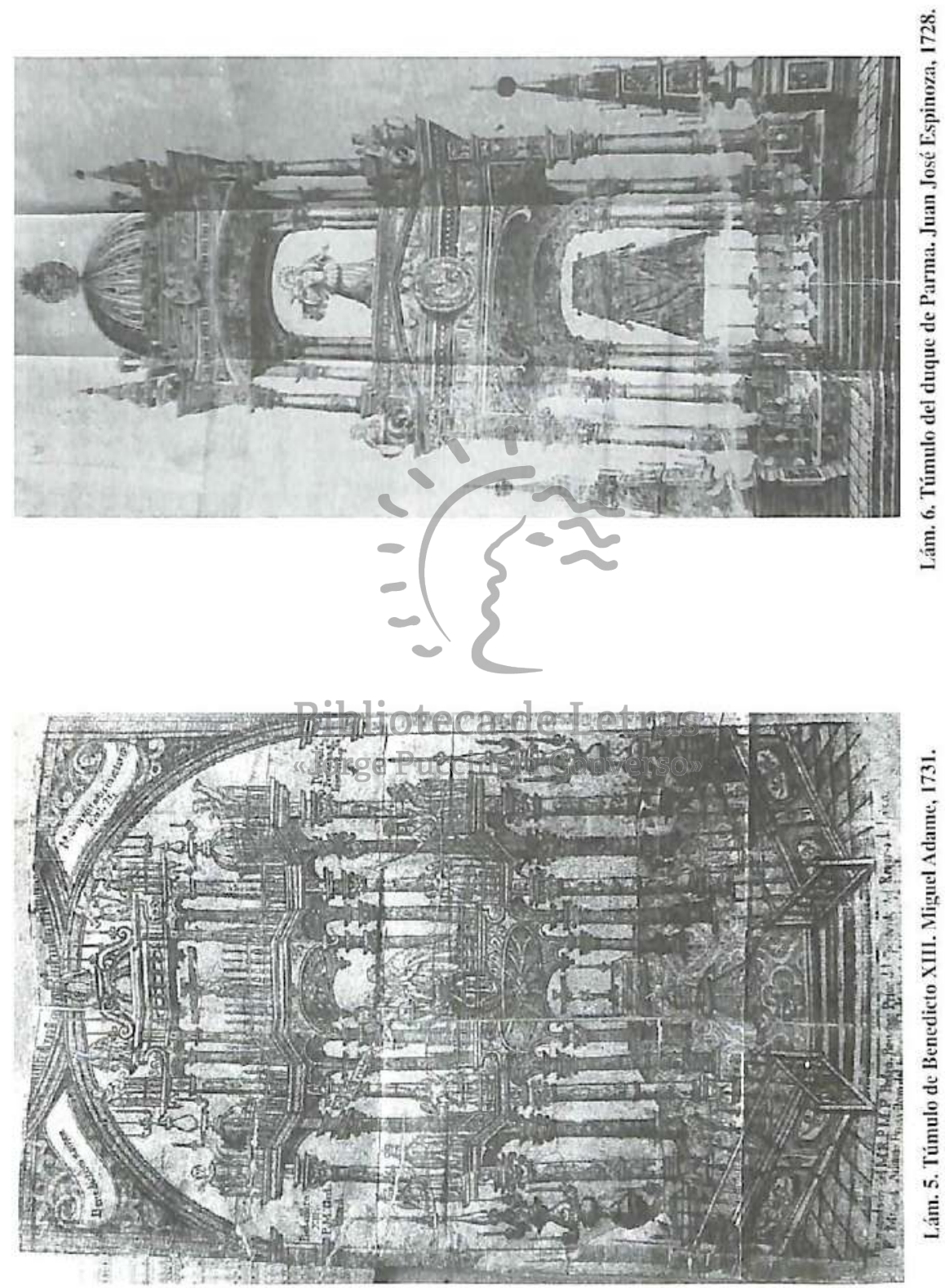

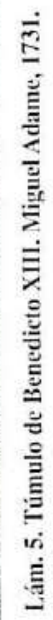




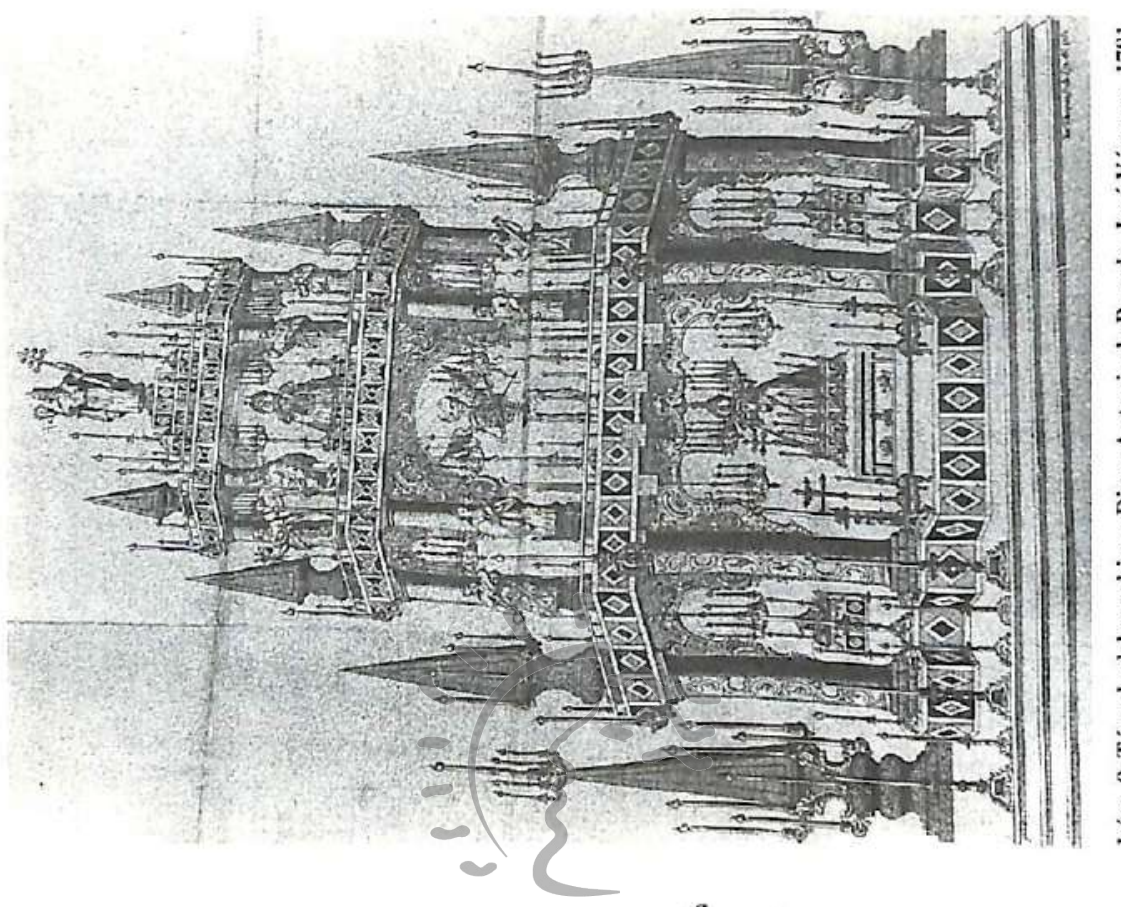



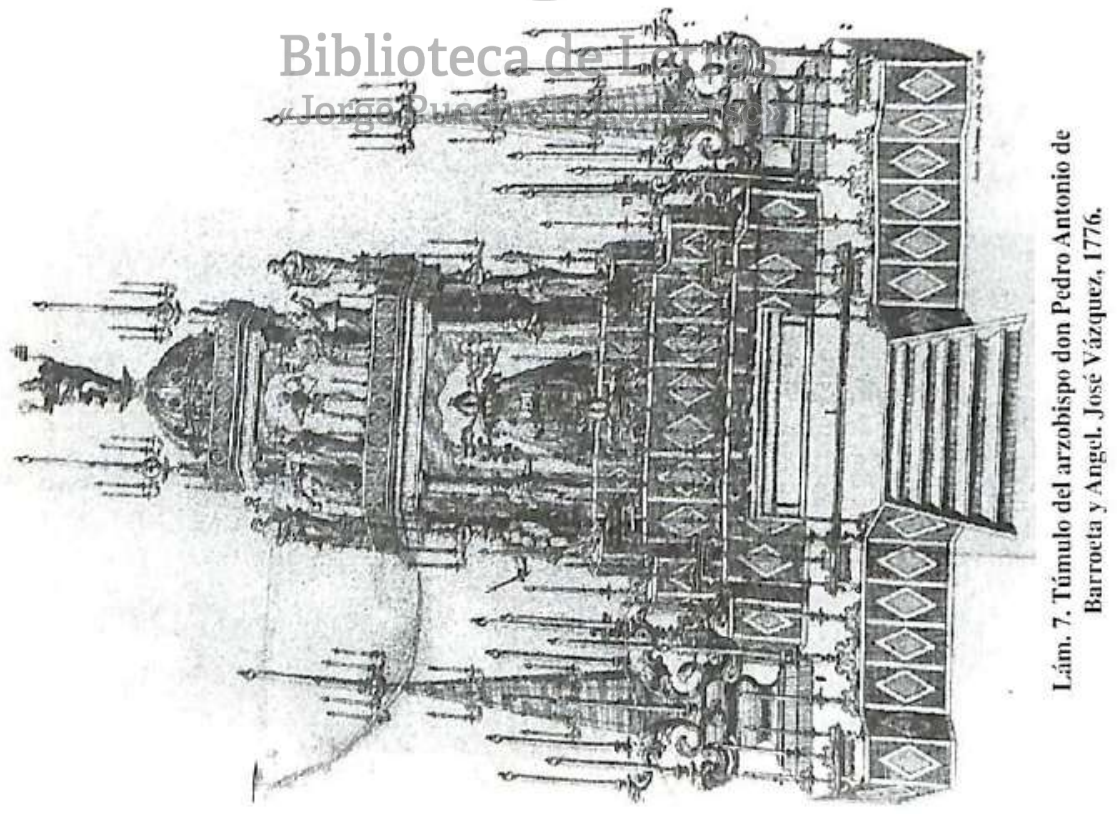




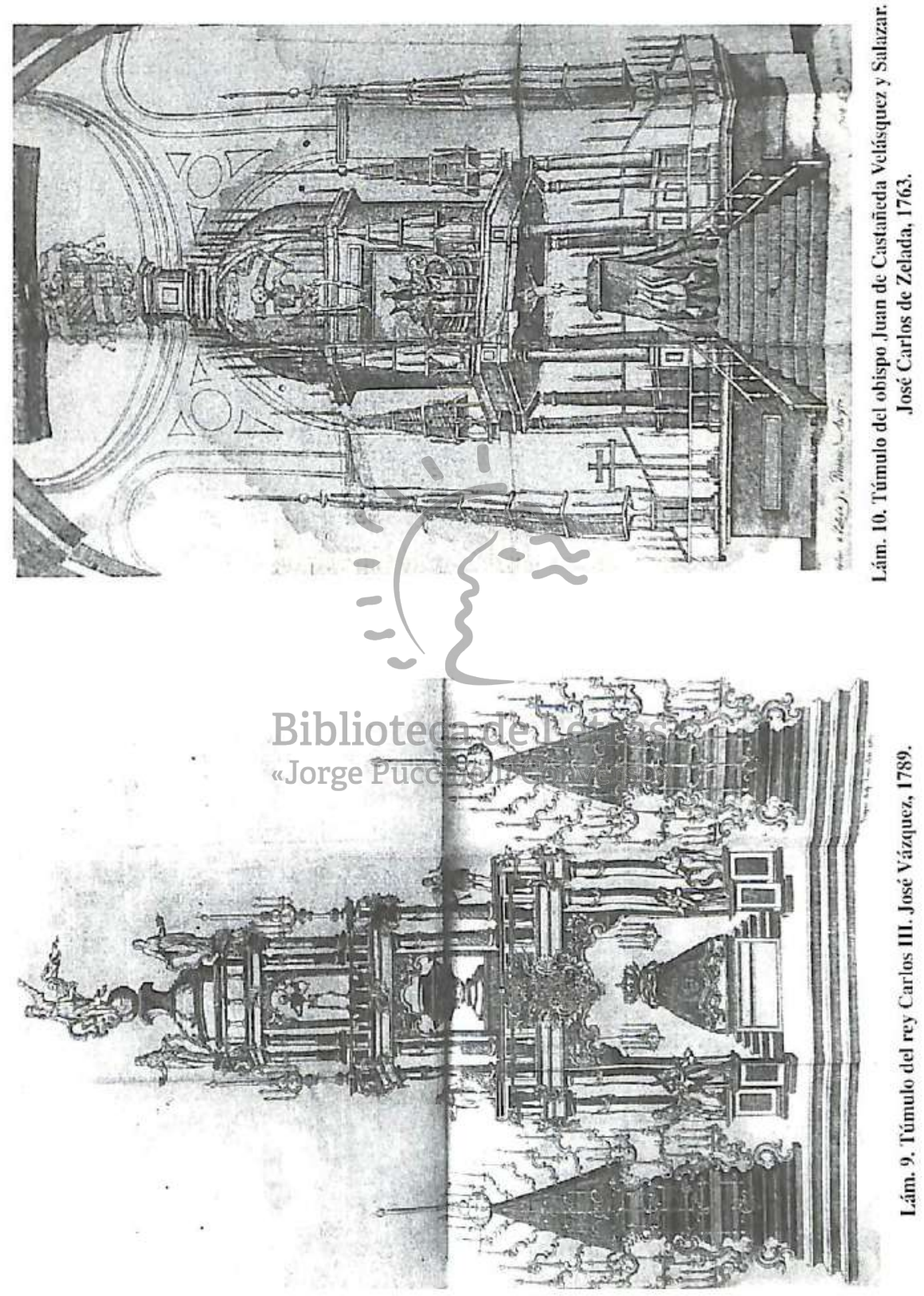



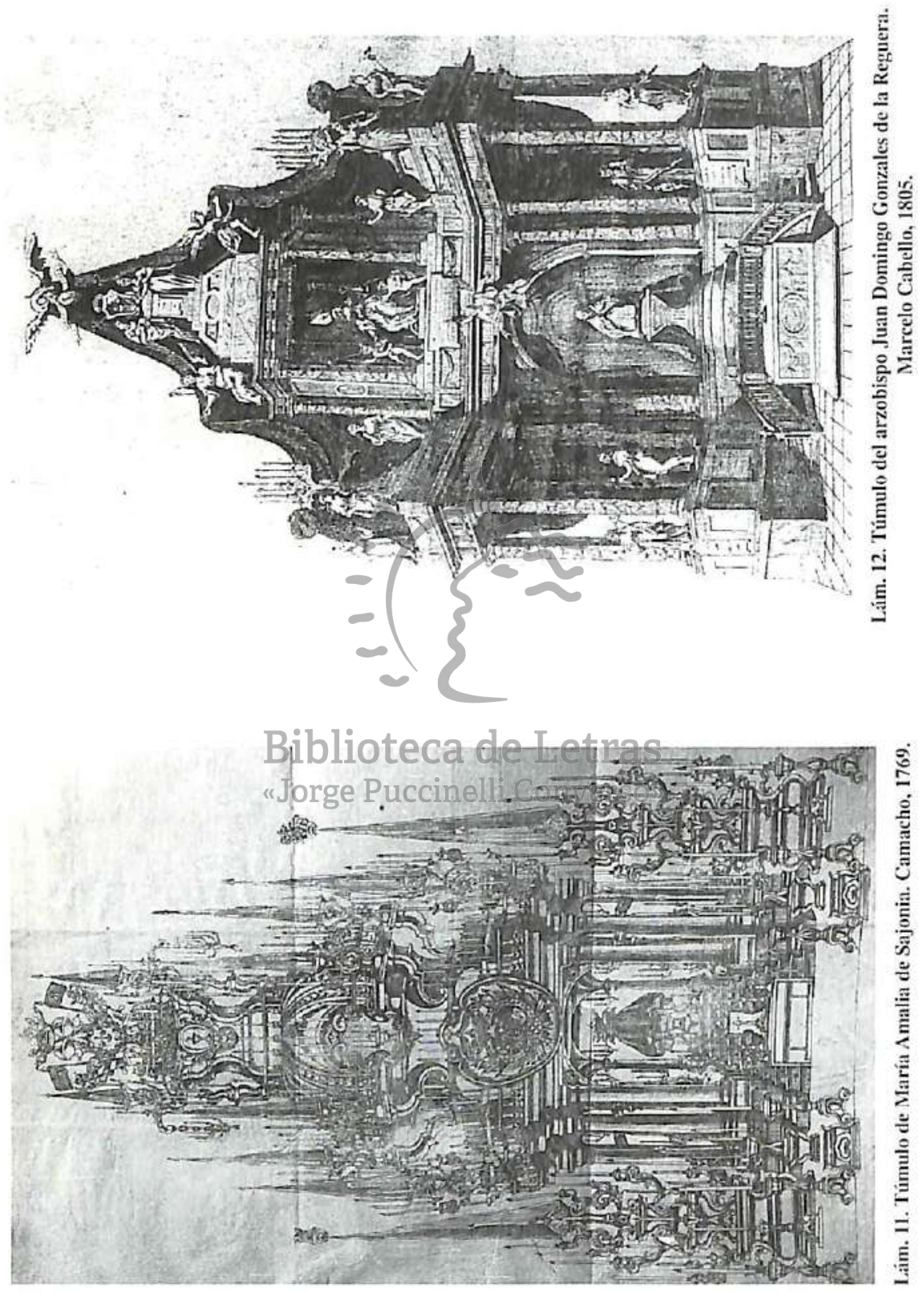